\title{
Disability is Diversity: A Multiculturalism Perspectives on Disability Inclusion in Higher Education
}

\author{
Nurjannah $^{1}$, Alies Poetri Lintangsari ${ }^{2}$, Unita Werdi Rahajeng ${ }^{3}$, Ucca Arawindha ${ }^{4}$ \\ \{nj_anna@ub.ac.id ${ }^{1}$, alieslintang@ub.ac.id ${ }^{2}$, unita@ub.ac.id ${ }^{3}$,ucca@ub.ac.id ${ }^{4}$ \} \\ Universitas Brawijaya, Indonesia ${ }^{1,2,3,4}$
}

\begin{abstract}
Debatable benefit of the emergent hegemonies view of disability as part of cultural diversity has increasingly discussed. This view has positively replaced the old schools (medical model, charity model and so forth) from seeing disability as impairment and oppression to seeing disability as one of cultural range (which is technically termed as cultural sub-variant or micro-cultural group). Of this premise, this paper seeks the potential of disability inclusion in higher education from cultural perspective. The objective of this research is to measure the index of inclusion in Indonesia higher education that focus on cultural dimension. Adopting index for inclusion by Tony Booth, this research invited 219 respondents consist of lecturers, staffs, students with and without disability from 12 universities in Indonesia to share their perspective in responding the disability inclusion in higher education. Descriptive statistics was applied to elicit the pattern of the data, the findings were elaborated through the multiculturalism perspectives. Issues, challenges and opportunity was expounded to address the cultural perspectives of university community in welcoming disability as part of cultural diversity.
\end{abstract}

Keywords: Disability Inclusion, Multiculturalism, Index for Inclusion, Disability is Cultural Diversity

\section{Introduction}

Defining disability involves the diverse values and theoretical proportions. Three major approaches in seeing disability lead how the mainstream community treat people with disability. Medical approach defines disability as a permanent biological impairment that posit people with disabilities as "less-able" than those who are not having disability. The medical approach defines disability within the physical, behavioral, psychological, cognitive and sensory misfortune. It puts disability within the individual problem rather than the social problems. Social model, on the other hands, defines disability as the social construction that leaves barriers such as attitudinal barriers such as negative attitudes, infrastructures barriers such as the inaccessible building, and policy barriers such as inaccessible policy that discriminate people with disability. Social approach postulates that the disability is socially constructed, thus, the locus of the problem is not the individual but the society. Social model is encouraging the removal of the barriers rather than "fixing" the person with disability. Multicultural model see disability as a part of cultural diversity as well as issues of race, class, gender and power differential [1][2].

Understanding disability within the context of multiculturalism as part of diversity with a minority status is not a novel idea [3]. Koppelman and Goodhart [4] debated that people with disabilities should be viewed as "minority group" which later termed as minority model, 
apparently this minority model leads the opinion that people with disabilities is the object of oppression [5]. It leads to discrimination that aside people with disabilities to education. For the past 25 years, the study of disability inclusion in higher education has risen [6][7][8][9]. This trend is likely initiated by the multicultural education. Multiculturalism has set out the opportunity to disability inclusion through the practices of multicultural education. It is a reform movement that invites the educational institution to change their system so they can welcome all students from all social-class, gender, racial, language, cultural group and different ability to have an equal opportunity to study [10][11][12][13]. As the increasing trend of multicultural education that grants the diverse meanings of culture and how its variables such as race, class, genders and also disability influence the education [13], seeing disability inclusion from multiculturalism perspectives invites new insight on how cultures treat disability as one of cultural diversity. Instead of seeing disability as an impairment, multicultural theorist tends to see disability as a cultural difference [5]. Additionally, Banks [12] terms disability with "exceptionality" that is considered as the multicultural subvariant or he defined as "microcultural group". As disability represent a particular part of human diversity, but it is not tolerably captured the common sense of cultural diversity [5], the presence of people with disability in inclusive context has challenged the concept of diversity and increasing the re-emergence of the related terms such as cultural pluralism and multiculturalism [3].

In the context of Indonesia higher education, access for students with disability remains exclusive although the government has guaranteed the equality of education under the law number 20 of 2003. Almost a decade after Indonesia ratified the UN CRPD through the law number 19 of 2011, the trends of including disability in higher education is increasing since the law make it more obligatory [7]. Employing the disability for inclusion framework [14] that specifically focused on cultural dimension, this article discusses the practices of disability inclusion in higher education settings in Indonesia and seeking the potential values of disability as part or cultural diversity through the lens of multiculturalism. Involving 219 respondents came from 12 Universities in Indonesia that has been practicing disability inclusion, this article captured the perspectives of university community (the leaders, the staffs, the lectures and the students) toward the disability inclusion in the higher education. A questionnaire developed based on Booth and Ainscow's [14] cultural dimension was translated into Indonesian and administered online. Face validity has been applied to guarantee the readability of the translation version, to guarantee the consistency of the questionnaire, statistical validity and reliability testing was implemented. Descriptive statistics was applied to explore the findings.

\section{Method}

\subsection{Participants}

219 participants from 12 Universities participated in this survey consist of $10.96 \%$ lecturers, $61.19 \%$ students without disabilities, $15.98 \%$ students with disabilities, $2.74 \%$ head of department, and $9.13 \%$ technical staffs. The students with disabilities participated in this research consist of $2.86 \%$ students with autism, $2.86 \%$ students with cerebral palsy, $2.86 \%$ students with mental disability, $28.57 \%$ students with physical disabilities, $20 \%$ deaf students, $37.14 \%$ blind students and $2.86 \%$ deaf-blind students. The variety of participants indicate that the data collected is objective. Table 1 provide the details information of participants 
demography. Data collection method is a purposive sampling by inviting the participants from Universities which had provided Disability Services.

Table 1. Participant's Demography

\begin{tabular}{lcc}
\multicolumn{3}{c}{ Table 1. Participant's Demography } \\
\hline \multicolumn{1}{c}{$\mathrm{N}$} & $\%$ \\
\hline Total & 219 & 100 \\
Lecturer & 24 & 10.96 \\
Staff & 19 & 9.13 \\
Head of Department & 8 & 2.74 \\
Students Without Disabilities & 134 & 61.19 \\
Students with Disabilities & 34 & 15.98 \\
\hline
\end{tabular}

\subsection{Instrument}

The questionnaire used in this survey is adapted from Index for Inclusion [14]. The Index for inclusion consists of 3 dimensions; cultural, policy, and practices, hence, this study only applied the cultural dimension. Booth and Ainscow [14] set out Cultural Dimension into two sub-dimensions; (1) Building inclusive community consists of 11 indicators and (2) Establishing inclusive values in education consists of 10 indicators, whereas, this study simplified those indicators into 10 of indicators represented the two sub-dimensions as explicated in table 2 .

Table 2. Indicator of Cultural Dimension

\begin{tabular}{clc}
\hline Item & \multicolumn{1}{c}{ Statement } & Subdimension \\
\hline C1 & All persons with disabilities are well welcomed & Culture 1: \\
C2 & All lecturers and staffs work together to support students with disabilities & Building \\
C3 & Students with disabilities and without disabilities support each other & inclusive \\
C4 & Mutual respect among students with disabilities and without disabilities & community \\
C5 & Campus inclusivity is supported by the surrounding environments. & \\
\hline C6 & $\begin{array}{l}\text { The entire campus community has knowledge and understanding of the } \\
\text { concept of inclusivity }\end{array}$ & \\
C7 & $\begin{array}{l}\text { Campus encourages all academic community to respect human rights } \\
\text { including the rights of persons with disabilities }\end{array}$ & Culture 2: \\
C8 & $\begin{array}{l}\text { Faculty/study programs crack down firmly on discriminatory treatment, } \\
\text { including to persons with disabilities }\end{array}$ & $\begin{array}{c}\text { Establishing } \\
\text { Inclusive }\end{array}$ \\
C9 & $\begin{array}{l}\text { Faculty/study programs implement non-violence policies, including for } \\
\text { persons with disabilities }\end{array}$ & values \\
C10 & All students are treated equally & \\
& & Source Adapted from Booth and Ainscow [14]
\end{tabular}

Source: Adapted from Booth and Ainscow [14].

\subsection{Research Design}

It is a survey research design with 5 Likert scale questionnaires adapted from index for inclusion developed by Booth and Ainscow [14] that focus on cultural dimension. Face validity and statistical validity and reliability was applied to ensure the consistency of the questionnaire. The descriptive statistical data analysis was employed to see the arrangement of data, parameter, scoring and visual data exploration. 


\subsection{Validity and Reliability}

Statistical testing was applied to ensure the validity and reliability of the questionnaire. Correlational statistics was applied to check the validity of the questionnaire and the reliability of the questionnaire was proved by the consistency of each question shown if the Alpha Cronbach coefficient score is $>0.6$. The validity and reliability test shown that all items are valid as shown in table 3 .

Table 3. Validity and Reliability Result

\begin{tabular}{cccccc}
\hline Indicator & \multicolumn{2}{l}{ Person Correlation } & Alpha Cronbach & Information \\
\hline Index 1 & 0.717 & $* * *$ & & Valid & \\
Index 2 & 0.758 & $* * *$ & & Valid & \\
Index 3 & 0.806 & $* * *$ & & Valid & \\
Index 4 & 0.765 & $* * *$ & & Valid & \\
Index 5 & 0.732 & $* * *$ & & Valid & Reliable \\
Index 6 & 0.681 & $* * *$ & 0.908 & Valid & \\
Index 7 & 0.836 & $* * *$ & & Valid & \\
Index 8 & 0.770 & $* * *$ & & Valid & \\
Index 9 & 0.687 & $* * *$ & Valid & \\
Index 10 & 0.684 & $* * *$ & Valid & \\
\hline
\end{tabular}

\section{Findings}

Descriptive statistics was employed to know the overview of how Indonesia higher education is culturally perceived. Data distribution is explained based on the respondent categories. Based on the respondent status as described in Chart 1, it is found that staff shows the highest average of culturally disability inclusion score ( 4.4 of 5 scale) followed by both of managers and students with disabilities ( 4.2 of 5 scales), students with disabilities ( 4 of 5 scale) and lecturers ( 4 of 5 scale).

Chart 1. Cultural Dimension Response based on Respondent Categories

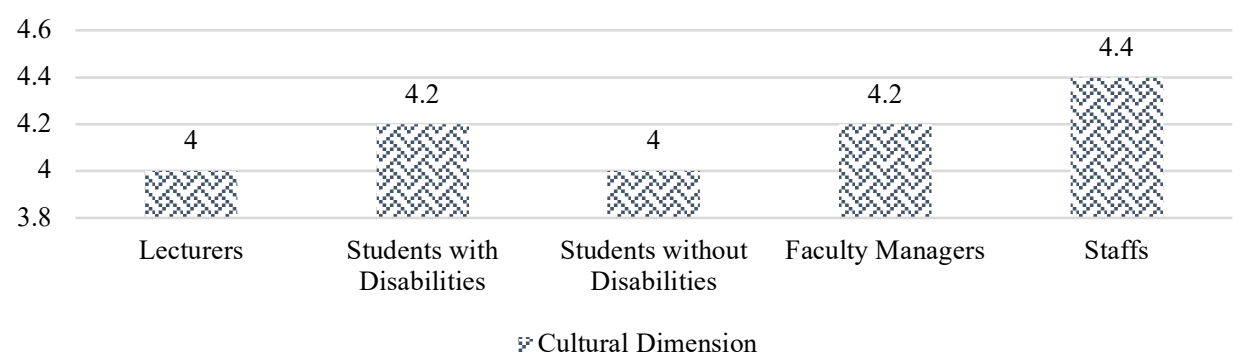

In terms of the sub dimension results, as seen in chart 2, the four respondent categories showed a higher average score for first dimension that is building inclusive curriculum rather than the second dimension that is establishing inclusive values. Staffs responses show 4.6 for the first dimension and 4.2 for the second dimension, the managers responded similar average between first and second dimension that is 4.2 , the average response of students with disabilities 
is 4 for the first sub dimension and 3.9 for the second sub dimension, the response of students without disabilities is 4.3 for first sub dimension and 4.1 for the second sub dimension while the response of the lecturers is 4.1 for the first sub dimension and 4 for the second sub dimension.

Chart 2. Culture Sub Dimensions Response

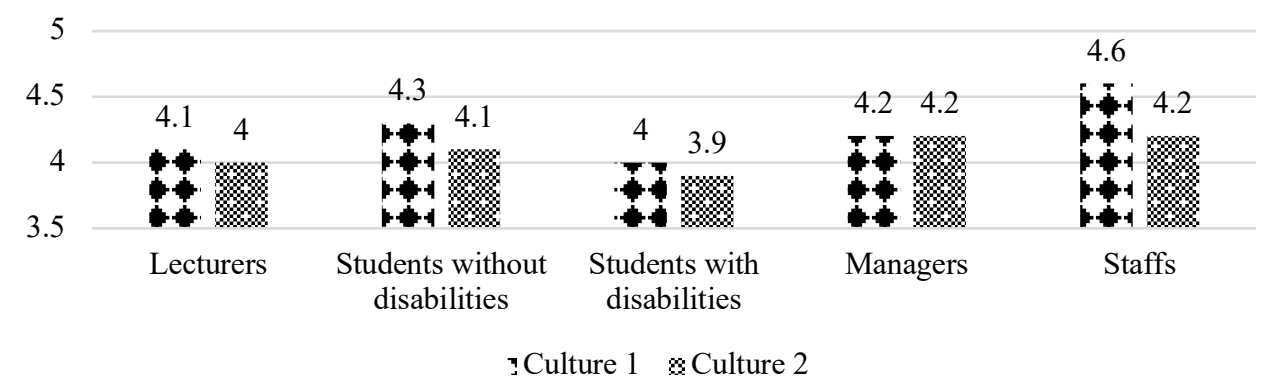

Chart 3 explores the scores of the cultures dimension responses based on the questions item. As seen in the chart, the top three items that reached the highest score are C4 (Mutual respect among students with disabilities and without disabilities) reached the highest score (4.39), followed by $\mathrm{C} 1$ (All persons with disabilities are well welcomed) with score 4.37, and tailed by $\mathrm{C} 10$ (All students are treated equally) with score 4.35 . While the least three items are C6 (The entire campus community has knowledge and understanding of the concept of inclusivity) with the lowest score 3.54, C8 (faculty/study programs crack down firmly on discriminatory treatment, including to persons with disabilities) with score 4.02 and C5 (Campus inclusivity is supported by the surrounding environments) with average score 3.11.

Chart 3. The Average of Cultural Dimension

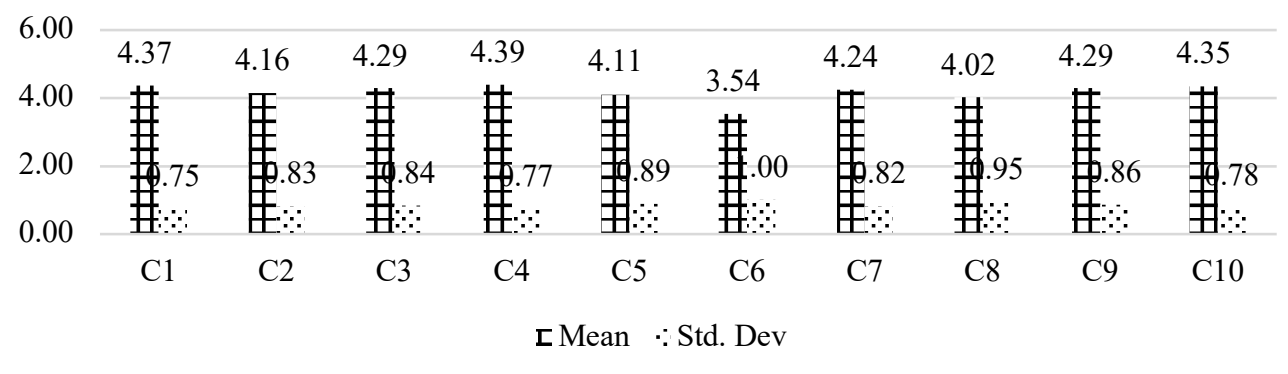

\section{Discussion}

Cultures mirror relationships, values and beliefs. It is essential in order to sustain inclusive development. Contesting the concepts of inclusive with multicultural, both of them are closely interconnected as both respect diversity. Diversity, thus, the locus of this discussion, has contributed to the shifting paradigm of seeing disability as impairment into seeing disability as cultural variety. As Booth and Ainscow [14] explicates that diversity includes the seen and unseen differences and similarities between people and it embraces everyone and welcomes difference within a common humanity. The dimension of culture holds a significant role in cultivating inclusive environment. Booth and Ainscow [14] sets out the cultural dimension as 
the first dimension in their index for inclusion. It consists of two sub dimensions; building community and establishing inclusive values. The average score explicates that the campus community tend to be more concern on building inclusive community rather than establishing inclusive values as the average score of building inclusive community is higher than establishing inclusive values. The interesting finding also found as this research revealed that highest average scores of the disability inclusion based on cultural dimension performed by the academic staffs $(4,4)$ and the lowest average score performed by the lecturers and students with disabilities (4).

This finding demonstrates that the academic staffs are more culturally sensitive and more appreciating disability as part of cultural diversity. This research replicated the research reported by Sakiz and Woods [15] that the school staffs in Turkey hold positive beliefs in the disability inclusion. The positive response of staff in cultural dimension of disability inclusion shows a promising inclusive practice since staffs provide services and supports the facilities for the students. On the other hand, the lecturer's cultural response toward disability inclusion in higher education is the lowest (4) among the other respondent's categories. Although in the average scores of the lecturer response is the lowest among the other, it is still in a good scale (4 of 5), it indicates that lecturers show a cultural-positive response towards the disability inclusion in higher education. Obisesan [16] argued that the positive response toward the disability inclusion of the lecturers is significant because it affects their attitudes in facilitating students with disability in mainstream context. Some factors that influence lecturers to welcome disability inclusion are the knowledge of reasonable adjustment, flexibility in teaching approach, workload demand, and the implementation of the adaptive curriculum [17].

Ensuring lecturers' positive attitudes and beliefs toward disability inclusion is significant as well as tailoring lecturers' competency and teaching skills in inclusive context to support students with disability in mainstream class [7]. Similar to the lecturer's cultural response toward disability inclusion, the students with disabilities also shows the lowest average among other respondents' category, instead, it is still in a good scale (4 of 5). It reflects that students with disabilities shows a positive cultural response toward disability inclusion in higher education as well as the students without disabilities that shows a higher average score (4.2). The diversity of students in educational context promoting the inclusive transformation, however, some potential challenges addressed by Fossey et al. [17] related to students with disability influencing factors toward inclusion needs to be account. Factors such as disability disclosures, knowledge of disability supports, awareness of their rights, using disability support, use alternative supports and accommodation, negotiation ability are considered as the factors influencing negotiation process in accessing disability supports that is affecting students with disabilities in actively participate in inclusive context [17]. The inclusion of disability in inclusive teaching settings has positively affected the teaching and learning practices such as positive behaviour support system between students with and without disability, the co-teaching practices between students with and without disability, variety of teaching method and strategies, and the exploration of the technology use [18]. Among the participation aforementioned parties in boosting disability inclusion in higher education, the roles of faculty managers are significant since they are the decision makers and managing the academic practices. The findings of the research show that the faculty managers response is in a good level (4.2 of 5). It indicates that the managers have positively supported the disability inclusion in higher education, moreover, the role of the managers is pivotal as they are not only facilitating the students in academic practical level but also giving emotional support, empathy and motivation [19].

The positive school culture is important to create a safe and comfort space for students to celebrate diversity and embracing differences. As this research explicated that the top three 
culture-based disability inclusion responses performed by all respondent category are; (1) mutual respect among students with and without disabilities (C4 with 4.39 of 5 scale); (2) All persons with disabilities are well welcomed (C1 with $4.37 \mathrm{pf} .5$ scale); and (3) all students are treated equally ( $\mathrm{C} 10$ with 4.35 of 5 scale), indicates that the disability inclusion has been culturally positively perceived by the campus community in Indonesia higher education although some challenges might be arisen such as the creating more engaging program and media related to the disability awareness and support socialization, encouraging the implementation of inclusive practices and involving the surrounding environments actively.

\section{Conclusion}

Multicultural education grants diversity as the enrichment of a nation to increase the ways of the community to perceive and solve personal and public problems by experiencing other cultures thus become more fulfilled as human beings. Multiculturalism's contribution to the disability inclusion in education has been positively bestowed. It has contributed in the transformation of the curriculum stressing on justice, equity, and sensitivity to the cultural differences in educational context [10]. Approaching disability with multicultural perspective is significant to promote disability as one of cultural diversity instead of impairment that positively affect the acceptance and the inclusion of disability in higher education settings and practices. As the findings reported that the average score of Indonesia university toward disability inclusion is positive, it indicates that the Universities in Indonesia are culturally ready for the disability inclusion although some challenges should be overcomes such as the disclosure of students with disabilities, the supports for lecturers and staffs to improve their competency and ability in providing inclusive services, and the disability awareness dissemination to improve a more positive response to the inclusive culture.

\section{Acknowledgement}

This paper is supported by Universitas Brawijaya, Indonesia under Research Grant 2020

\section{References}

[1] S. F. Gilson and E. Depoy, "Multiculturalism and disability: A critical perspective," Disabil. Soc., vol. 15, no. 2, pp. 207-218, 2000.

[2] A. Hodkinson, "Inclusive education and the cultural representation of disability and Disabled people: recipe for disaster or catalyst of change? An examination of non-disabled primary school children's attitudes to children with disabilities," Res. Educ., vol. 77, no. 1, pp. 56-76, 2007.

[3] S. O’Connor, "Multiculturalism and Disability: A Collection of Resources.," 1993.

[4] K. L. Koppelman and R. L. Goodhart, Understanding human differences: Multicultural education for a diverse America. Pearson/Allyn and Bacon, 2005.

[5] D. Anastasiou, J. M. Kauffman, and D. Michail, "Disability in multicultural theory: Conceptual and social justice issues," J. Disabil. Policy Stud., vol. 27, no. 1, pp. 3-12, 2016.

[6] D. Hernández-Torrano, M. Somerton, and J. Helmer, "Mapping research on inclusive education since Salamanca Statement: a bibliometric review of the literature over 25 years," Int. J. Incl. Educ., pp. 1-20, 2020.

[7] A. P. Lintangsari and I. Emaliana, "Inclusive Education Services for the Blind: Values, Roles, 
and Challenges of University EFL Teachers.," Int. J. Eval. Res. Educ., vol. 9, no. 2, pp. 439-447, 2020 .

[8] K. Nes, "The role of the index for inclusion in supporting school development in Norway: A comparative perspective," Res. Comp. Int. Educ., vol. 4, no. 3, pp. 305-320, 2009.

[9] L. Stentiford and G. Koutsouris, "What are inclusive pedagogies in higher education? A systematic scoping review," Stud. High. Educ., pp. 1-17, 2020.

[10] J. A. Banks, Multicultural Education: For Freedom's Sake. Seattle: University of Washington, 1991.

[11] J. A. Banks, "Multicultural education: Development, dimensions, and challenges," Phi Delta Kappan, vol. 75 , no. 1, pp. 22-28, 1993.

[12] J. A. Banks, Cultural Diversity James A Banks. Seattle: University of Washington, 2000.

[13] J. A. Banks and C. A. M. Banks, Multicultural education: Issues and perspectives. John Wiley \& Sons, 2019.

[14] T. Booth and M. Ainscow, Index for inclusion: Developing learning and participation in schools. ERIC, 2002.

[15] H. Sakiz and C. Woods, "From thinking to practice: school staff views on disability inclusion in Turkey," Eur. J. Spec. Needs Educ., vol. 29, no. 2, pp. 135-152, 2014.

[16] O. Obisesan, "Teacher attitudes, cultural beliefs, and problems experienced teaching children with disabilities in Nigeria," 2020.

[17] E. Fossey, L. Chaffey, A. Venville, P. Ennals, J. Douglas, and C. Bigby, "Navigating the complexity of disability support in tertiary education: perspectives of students and disability service staff," Int. J. Incl. Educ., vol. 21, no. 8, pp. 822-832, 2017.

[18] K. A. Shogren et al., "The perspectives of students with and without disabilities on inclusive schools," Res. Pract. Pers. with Sev. Disabil., vol. 40, no. 4, pp. 243-260, 2015.

[19] M. Khouri, O. Lipka, and M. Shecter-Lerner, "University faculty perceptions about accommodations for students with learning disabilities," Int. J. Incl. Educ., pp. 1-13, 2019. 